\title{
ESTUDO COMPARATIVO DE CARACTERISTICASS DO PACIENTE QUEIMADO NUMA UNIDADE ESPECIALIZADA DE INTERNAÇAO
}

\author{
* Elza Maria Lima dos Santos \\ ** Maurilio Nunes Pereira
}

\begin{tabular}{l|l|} 
& RBEn/09 \\
\hline
\end{tabular}

SANTOS, E.M.L. e colaborador - Estudo comparativo de características do paciente queimado numa unidade especializada de internaçāo. Rev. Bras. Enf.; DF, 31 : 68-73, 1978.

\section{INTRODUÇĀO}

Desde $o$ início das atividades do Centro de Tratamento de Queimados, verificou-se a alta incidência de hospitalização nas diversas faixas etárias, e particularmente a diversificação do agente causal.

Para os profissionais da equipe de enfermagem, a preocupação torna-se. maior por estarem envolvidos com este tipo de paciente, que requer tratamento especializado e pessoal altamento qualificado. Considera-se o grande queimado uma situação de alto risco, dada a complexidade do quadro apresentado onde se evidencia: alteraçōes anátomofisiológicas, susceptibilidade à infecção, grande dependência física e emocional e distúrbio do comportamento. Ressal- ta-se que a assistência a este paciente torna-se por demais estressante.

Por outro lado, observa-se que as situaçōes nas quais ocorre o acidente, sãc em grande maioria semelhantes e pode. riam ser evitadas, conforme o estudo realizado, analizando-se um grupo de pacientes e comparando-se as suas características.

\section{OBJETIVOS}

- Demonstrar a alta incidência ce hospitalização por queimaduras nas diversas faixas etárias.

- Indicar os agentes causais que ocorrem com maior frequência.

- Revelar as causas que levam 0 indivíduo a queimar-se.

* Enfermeira do Centro de Tratamento de Queimados do Hospital do Andarai INPS. RJ

Auxiliar de Ensino da Escola de Enfermagem da FEFIERJ.

** Enfermeiro do Centro de Tratamente de Queimados do Hospital do Andarai INPS. RJ 
SANTOS, E.M.L. e colaborador - Estudo comparativo de características do paciente queimado numa unidade especializada de internaçāo. Rev. Bras. Enf.; DF, 31 : 68-73, 1978.

\section{METODOLOGIA}

\section{AMOSTRA ESTUDADA:}

Compuseram a amostra todos os 534 casos de internação ocorridos no Centro de Tratamento de Queimados do Hospital do INPS - Andarai - RJ, no período de dezenove meses consecutivos à partir de maio de 1975.

\section{INSTRUMENTO:}

Foi utilizado um livro próprio para a pesquisa, onde os enfermeiros após observação, entrevista com o paciente ou familiares e avaliação de cada cas̄o durante a admissão, registraram os seguintes dados:
a) idade do paciente;
b) sexo;
c) agente causal ;
d) causa;
e) superfície corporal queimada.

\section{LEVANTAM?NTO:}

Através dos dados coletados e registrados, realizou-se o seguinte levantamento:

3.1. Incidência de queimaduras por faixa etária:

- 0 a 5 anos;

- 5 a 10 anos;

- 10 a 15 anos;

-15 a 20 anos;

-20 a 25 anos;

-25 a 30 anos;

- 30 a 35 anos;

- 35 a 40 anos;

- 40 a 45 anos;

-45 a 50 anos;

- 50 a 55 anos;

- 55 a 60 anos;

- 60 a 65 anos;

- 65 a 70 anos;

- acima de 70 anos.
3.2. Incidência de queimaduras em relação ao agente causal:

- álcool, gasolina, querosene, óles, gaz, líquido, panela de pressão, tinta, pólvora, pneu, cola, vela, piche e outros.

3.3. Incidência de queimaduras quanto à causa:

- acidente doméstico;

- acidente de trabalho;

- tentativa de suicídio;

- raios solares;

- acidente de trânsito;

- outros.

\section{RESULTADOS}

TABELA I

INCIDENCIA DE QUEIMADURAS POR FAIXA ETARIA

\begin{tabular}{lrc}
\hline FAIXA ETARIA & ABS & \multicolumn{1}{c}{$\%$} \\
\hline 0 a 5 anos & 124 & 23,22 \\
5 a 10 anos & 90 & 16,85 \\
10 a 15 anos & 55 & 10,30 \\
15 a 20 anos & 27 & 5,05 \\
20 a 25 anos & 55 & 10,30 \\
25 a 30 anos & 43 & 8,05 \\
30 a 35 anos & 35 & 6,55 \\
35 a 40 anos & 26 & 4,86 \\
40 a 45 anos & 23 & 4,30 \\
45 a 50 anos & 17 & 3,20 \\
50 a 55 anos & 9 & 1,70 \\
55 a 60 anos & 10 & 1,87 \\
60 a 65 anos & 11 & 2,05 \\
65 a 70 anos & 4 & 0,75 \\
acima de 70 anos & 4 & 0,95 \\
\hline TOTAL & 534 & 100,00 \\
\hline
\end{tabular}


SANTOS, E.M.L. e colaborador - Estudo comparativo de caracteristicas do paciente queimado numa unidade especializada de internaçāo. Rev. Bras. Enf.; DF, 31 : 68-73, 1978.

TABELA II

\section{INCIDENCIA DE QUEIMADURAS EM RELAÇÃO AO AGENTE CAUSAL}

\begin{tabular}{lrr}
\hline \multicolumn{1}{c}{ AGENTE CAUSAL } & ABS & \multicolumn{1}{c}{$\%$} \\
\hline Álcool & 269 & 50,38 \\
Liquidos Aquecidos (*) & 118 & 22,10 \\
Gasolina, Querosene, Óleo & 41 & 7,70 \\
Gás & 33 & 6,18 \\
Raios Solares (praia) & 12 & 2,25 \\
Panela de Pressão & 7 & 1,31 \\
Eletricidade & 6 & 1,12 \\
Tinta & 5 & 0,93 \\
Cola Industrial & 4 & 0,74 \\
Pólvora & 3 & 0,57 \\
Pneu & 2 & 0,37 \\
Vela & 2 & 0,37 \\
Piche & 2 & 0,37 \\
Outros (**) & 30 & 5,61 \\
\hline \multicolumn{1}{c}{ TOTAL } & 334 & 100,00 \\
\hline
\end{tabular}

(*) Líauidos Aquecidos: água fervente, café, leite, mingau, feijāo, óleo de cozinha, sopa, molho, chá, parafina.

(**) Outros: colchão em chamas, caldeira. fogareiro de lenha, cigarro, fogueira, brasa, isqueiro. jornal em chamas, lixeira, ferro elétrico e espiral contra insetos.

\section{ANÁLISE E RECOMENDAÇŐES}

\section{I - Analisando-se a Tabela I observa- se que:}

A grande incidência de pacientes queimados está na faixa etária de 0 a 5 anos $(23,22 \%)$. Considerando-se que nesta fase, a criança experimenta as emoçōes das descobertas, é importante que a vigilância seja rigorosa, objetivando fornecer-lhe maior proteção.

Destaca-se a incidência de queimaduras em crianças na faixa etária de 0 a 1 ano $(7,50 \%)$.
TABELA III

INCIDENCIA DE QUEIMADURAS QUANTO A CAUSA

\begin{tabular}{|c|c|c|}
\hline $\begin{array}{l}\text { CAUSA DA } \\
\text { QUEIMADURA }\end{array}$ & ABS & $\%$ \\
\hline Acidente Doméstico (*) & 441 & 82,59 \\
\hline Acidente de Trabalho & 39 & 7,31 \\
\hline Tentativa de Suicídio & 26 & 4,81 \\
\hline Raios Solares (praia) & 12 & 2,24 \\
\hline Acidente ce Trânsi'u & 6 & $1,1^{\prime}$ \\
\hline Outros & 10 & 1,87 \\
\hline TOTAL & 534 & 100,00 \\
\hline
\end{tabular}

(*) Acidente Doméstico: atividades de cozinha, treca de botijāo de gás, tratamento medicamentoso, pesquisas escolares, brincadeiras de criança, vaporizaçōes improvisadas, agressōes (tentativas de homicídio), festejos juninos, reparos caseiros, limpeza doméstica, pintura de parede.

Isto revela inabilidade e descuido dos pais ou responsáveis, considerando-se ser esta faixa etária de completa dependência, cabe um alerta aos profissionais da equipe de saúde, no sentido de promover a Educaçāo para a Saúde, utilizando-se as oportunidades de orientação às māes em ambulatórios e centros de saúde.

Na elevada incidência nas faixas etárias de 5 a 10 anos $(16,85 \%)$, constatamos que muito contribuiu para que isto ocorresse: o incentivo às pesquisas quimicas, por parte das escolas. Sem observarem as orientaçōes de precauçōes necessárias, as crianças em grupos empre- 
SANTOS, E.M.L. e colaborador - Estudo comparativo de características do paciente queimado numa unidade especializada de internaçăo. Rev. Bras. Enf.; DF, 31 : 68-73, 1978.

gavam o álcool para desenvolverem o estudo. te grande importância a divulgação de orientaçōes sobre as precauçōes para estes grupos, pais, professores e alunos, usando recursos de grande penetração.

Conforme ressaltamos, a incidência de crianças queimadas, somadas as três faixas etárias, representa um percentual muito elevado $(50,37 \%)$. Diante dos resultados obtidos, é necessário a exdstência de enfermarias especializadas em pediatria, no Centro de Tratamento de Queimados.

Somadas as faixas etárias de 30 a 50 anos, constatou-se a incidência de $18,91 \%$. Sendo esta a faixa de grande produtividade, pode-se concluir que sob o ponto de vista sócio-econômico isto resulta em grande problema social, com o aumento considerável do número de inválidos ou incapacitados, por sequelas de queimaduras.

II - Na tabela II constatamos que:

Os resultados obtidos mostraram que o maior AGENTE CAUSAL de queimaduras é o ÁLCOOL $(50,38 \%)$, devido a falta de atenção no manuseio das garrafas plásticas.

Em segundo lugar observamos a incidência de queimados por líquidos aquecidos $(22,10 \%)$. Isto leva-nos a propor um programa de orientação à po. pulação, principalmente'às mães, visando uma maior atenção na manipulação dos mesmos e no sentido de não permitirem a permanência das crianças em locais que propiciem acidentes.

A incidência de queimados por GASOLINA; QUEROSENE e ÓLEO é de $(7,70 \%)$. Por apresentarem o mesmo tipo de queimaduras, foram agrupadas, revelando uma não observância das normas de prevenção de acidente de trabalho.
A incidência de queimaduras por GAS é também fator considerável $(6,18 \%)$. Chamando por uma maior divulgação junto aos usuários, quanto às precauçōes no manuseio do mesmo.

Os demais AGENTES CAUSAIS, numa diversificação considerável, não apresentam incidência notável.

III - Tabela III revelou os seguintes dados:

Considerando-se a CAUSA, a grande incidência de queimaduras, foi alcançada no ACIDENTE DOMÉSTICO $(82,59 \%)$. Nele foi incluido os acidentes com crianças no lar, com domésticas e com homens em atividades caseiras.

$A$ incidência de queimaduras em ACIDENTE DE TRABALHO não foi muito elevada $(7,31 \%)$. Contudo, os casos pesquisados são suficientes para incentivar uma maior observação das normas de prevenção de acidentes de trabalho tanto pela empresa, oferecendo segurança, como pelo empregado, no cumprimento das normas de segurança.

Observa-se uma incidência de 4,81\% em TENTATIVA DE SUICIDIO, embora seja o mais traumatizante recurso de auto-exterminio. Constata-se uma prevalência no sexo feminino e em ambos os sexos por pessoas com distúrbios psíquicos.

Constituindo-se uma pequena incidência, observa-se como causa de acidentes, a PRAIA, por prolongada exposição aos raios solares e aplícação de bronzeadores de fabricação caseira, empregando a solução de meladinime.

Uma incidência relativamente pequena de queimaduras em ACIDENTES DE TRANSITO, por incêndio de moto ou automóvel após colisão, já constatada. 
SANTOS, E.M.L. e colaborador - Estudo comparativo de características do paciente queimado numa unidade especializada de internaçāo. Rev. Bras. Enf.; DF, 31 : 68-73, 1978.

\section{REPRESENTAÇÃO GRAFICA DA INCIDENCIA DE QUEIMADURAS QUANTO $\AA$ CAUSA}

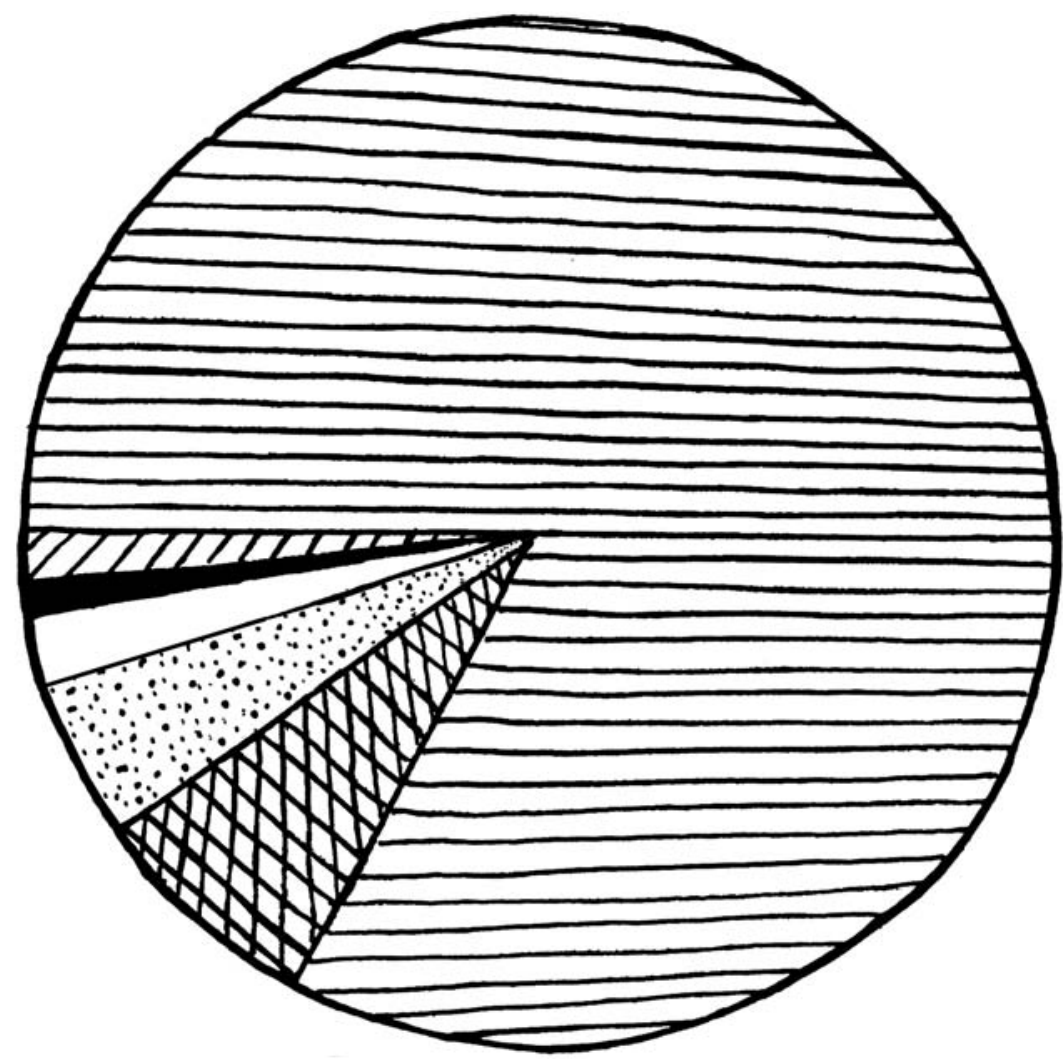

$\underline{L} \underline{E} \underline{G} \underline{\mathrm{N}} \underline{\mathrm{D}} \underline{\mathrm{A}}$

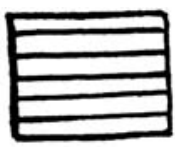

acidentes

domésticos

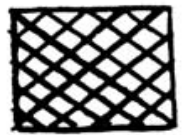

acidentes de trabalho

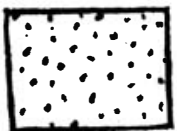

tentativa de suicídio

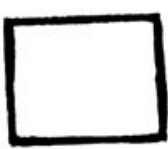

Raios solares

(praia)

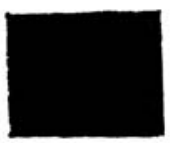

trânsito

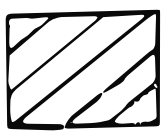

outros 
SANTOS, E.M.L. e colaborador - Estudo comparativo de características do paciente queimado numa unidade especializada de internaçāo. Rev. Bras. Enf.; DF, 31 : 68-73, 1978.

\section{CONCLUSÃO}

Diante da problemática dos acidentes por queimaduras, justifica-se ainda a necessidade de centros especializados para o tratamento destes pacientes, que pela extensão da área queimada, requerem ambiente com características especiais, propiciando maior segurança quanto a assepsia no tratamento. Por ser necessário equipes especializadas na assistência ao paciente e manuseio da aparelhagem especifica, torna-se imprescindível o treinamento de pessoal de enfermagem qualificado para atuação nestas unidades.

A situação-das queimaduras é muito séria e exige interesse por parte dos elementos que trabalham na equipe de saúde aplicando os princípios de Educação para a saúde a fím de que esse indices sejam reduzidos.

\section{REFERENCIAS BIBLIOGRAFICAS}

1. ALVES, J. B. de Resende - CIRUR GIA GERAL E ESPECIALIZADA. 2. Vol. Editora Vega - Instituto Nacional do Livro. Belo Horizonte,

2. CERVO, A. L. \& BERVIAN, P. A: - METODOLOGIA CIENTAFICA. Editora McGraw-Hill do Brasil. Ltda, 1974.

3. CIETTO, Luiz - PESQUISA E DESENVOLVIMENTO DA ENFERMAGEM: CONSWERAÇOES SOBRE A IMPORTANCIA NA AREA MATERNO-INFANTIL. Rev. Enfermagem em Novas Dimensôes 2 (2): 93-97, 1976.

4. INFORME FINAL DE LA REUNION ESPECIAL DE MINISTROS DE SALUD. PARTE III - METAS DEL PLANO DECENAL DE SALUD DE LAS AMERICAS, PARA EL DECENIO 1971 - 1980. Realizado em Santiago do Chile - Outubro de 1972.
5. KOIZUMI, M. S. \& CHIARELLO, M. L. - ESTUDO PRELIMINAR SOBRE A EFETIVIDADE DE UM ROTEIRO PARA EXAME FISI. CO APLICADO EM PACIENTES NEUROCIRURGICOS. Rev. Enfermagem em Novas Dimensōes 2 (6) : 330-336, 1976.

6. RAMOS NETO, M. O.; MARCHIORI, M. E.; TAJIKI, S.; MOTTOS, T. - PESQUISA EM ENFERMAGEM: ASPECTOS ETICOS. Rev. Enfermagem em Novas Dimensōes - 2 (5): 295-299, 1976.

7. RUSSO, Ary do Carmo - TRATAMENTO DAS QUEIMADURAS. 2." Ed. Editora Sarvier. S. Paulo, 1976.

8. VIVEIROS DE CASTRO. L. S. PONTOS DE ESTATISTICA. Editora Científica, Rio de Janeira 1970. 